\title{
Using an observation tool (Parent-Infant Interaction Observation Scale) to assess parent-infant interaction in the first 2 weeks of life: A feasibility study
}

\author{
Aideen Naughton $^{1,4}$ (D) | Lucinda Perkins ${ }^{2}$ | Bethan McMinn ${ }^{3}$ | Alison Kemp ${ }^{4}$
}

\footnotetext{
${ }^{1}$ National Safeguarding Team, Public Health Wales, Cardiff, Wales

${ }^{2}$ Neonatal Unit, Singleton Hospital, Swansea, Wales

${ }^{3}$ Community Child Health Division, Singleton Hospital, Swansea, Wales

${ }^{4}$ Division of Population Medicine, School of Medicine, Cardiff University, Cardiff, Wales

Correspondence

Dr. Aideen Naughton, Public Health Wales,

Caerleon House, Mamhilad Park Estate,

Pontypool, NP4 OHZ, UK.

Email: aideen.naughton@wales.nhs.uk
}

\begin{abstract}
Background: Emotional maltreatment (EM) has profound effects on the developing brain but is hardest to identify in infancy. Early observations of parent-infant interactions may provide opportunities to identify babies at risk of neglect and EM. This prospective study tests, in the first fortnight of life, the feasibility of using an observation tool previously validated for use at 2 to 7 months of age.

Methods: Women awaiting induction of labour were recruited in South Wales in July 2016. Women consented to being contacted postnatally and video recordings of mother-infant interaction at two home visits between 7 and 10 days (T1) and 812 weeks old (T2). Demographic details, information on the pregnancy, delivery, and infant condition were obtained at T1. A questionnaire was completed at T2 to capture any significant events affecting the parent-infant relationship. The Parent-Infant Interaction Observation Scale (PIIOS) was used to score the videos. Exclusion criteria included admission to neonatal unit.
\end{abstract}

Results: Recruitment of suitable participants and full research data completion were feasible. Of 60 women who consented to be contacted post-delivery, 30 women (31 infants) participated at $\mathrm{T} 1$ and $\mathrm{T} 2$. Three babies were excluded. Women accepted being observed in their homes with their babies, with no attrition between T1 and T2. Using the PIIOS 10 of the 13 items could be scored with an awake infant under 2 weeks.

Conclusion: These encouraging findings can inform exploration of an observation tool to identify high-risk dyads for targeted support. A trial and test of a modified scoring system (based on the PIIOS) should be developed for a future study using a larger sample size. Further research should assess if this approach reliably produces a consistent valid screening tool to assess parental sensitive responsiveness and resilience promoting behaviours at this early stage of life.

KEYWORDS

child development, early assessment, emotional well-being, mother-infant interaction 


\section{1 | INTRODUCTION}

During childhood, emotional development is largely dependent upon the quality of parent-child interactions. Neglect and emotional abuse represent extreme departures from the average expected caregiving environment; many of the developmental deficits associated with these forms of maltreatment can be explained by a lack of appropriate parent-child interactions. The medical, social, and psychological consequences of this maltreatment persist through to adulthood. Published work has documented the emotional, behavioural, or developmental features observable in children experiencing neglect or emotional abuse (Maguire et al., 2015; Naughton et al., 2013), however less attention has been paid to parent-child relationships.

Infant-parent attachment plays a fundamental, environmental role on the infant's rapidly developing nervous system. (Balbernie, 2001; Balbernie, 2013; Schore, 1994). The attachment system evolved to ensure that relatively helpless young maintain a close proximity to a protective adult when under threat (Ainsworth, Blehar, Waters, \& Wall, 1978; Balbernie, 2001; Bowlby, 1982). The parent's sensitivity to the infant's feelings-the ability to tune into the baby's internal state and offer appropriate help to keep it modulated within comfortable limits-determines the quality of the attachment relationship (Balbernie, 2013). High parental "sensitive responsiveness" is characteristic of a positive interaction (Crittenden \& Bonvilian, 1984). The "sensitive period" hypothesis suggests that, while acknowledging how early life informed social relationship patterns impact profoundly on later normal development, they are not irreversible; so the early years are a highly significant or sensitive period for the development of social relationships rather than a critical period.

Secure attachment, imperative for positive emotional child development, is associated with optimal later functioning across a range of domains; scholastic, emotional, social, and behavioural, and peerrelated social status. Whereas, insecure attachment is associated with compromised development across these domains, and disorganised attachment is associated with significant later psychopathology. (Svanberg, Barlow, \& Tigbe, 2013). Preventing these long-lasting adverse outcomes requires early identification of babies at risk of neglect and emotional abuse through observation of the emerging insecure/disorganised infant-parent attachment and implementation of evidence-based interventions.

This understanding of the key role that the caregiving relationship plays in infant brain development and future psychosocial well-being, has led to recognition of the importance of early intervention for problematic parenting during the first years of life. In recent years, the Departments of Health in England and Wales have revised their Healthy Child Programme, placing a new emphasis on attachment and positive parenting (Department of Health, 2009; Welsh Government, 2016). However, in 2010 published research highlighted that health visitors, who have a key role in recognising disordered parenting, were inconsistent in their professional assessments of parentinfant interaction (Appleton, Harris, \& Oates, 2010). This points to the need to improve the skills of wide ranging groups of practitioners in their ability to recognise severely compromised parent-infant interaction. Another obstacle is the lack of access to valid and reliable screening tools that can be used by frontline practitioners. Existing

\section{Key messages}

- Mothers accepted having their interactions with their babies video recorded in the first 2 weeks.

- Ten out of 13 items using the Parent-Infant Interaction Observation Scale (PIIOS) could be scored at 2 weeks old.

- A modified scoring system based on the PIIOS should be tested on a larger sample size.

- Further study needed to assess tool reliability and validity for screening parental attunement this early in life.

measures of parent-child interaction have a number of limitations, and many are not suitable for use by primary care practitioners or require quite lengthy training to achieve rater reliability (Table 1).

The Parent-Infant Interaction Observation Scale (PIIOS) was designed to enable practitioners working in early years and primary care settings to easily assess parental sensitive responsiveness with babies between the ages of 2 and 7 months of age through recorded observation of the parent infant interaction over a 3-min period. The tool includes a number of constructs based on the work by Ainsworth and Crittenden (Biringen, 2000). It incorporates research on "mindmindedness" (Meins, Fernyhough, Wainright, Clark-Carter, \& Das Gupta, 2003), in which the mother shows an ability to interpret and verbalise the baby's thoughts or motivations, a predictor of infant attachment security (Meins, Fernyhough, Fradley, \& Tuckey, 2001). Drawing on these constructs, the PIIOS guides the practitioner to consider the observed interaction with three "interactional" dimensions in mind: engagement, varying from over intrusiveness to nonengagement; predictability, varying from being predictable to being unpredictable; genuineness varying from true and genuine affect to false and deceptive affect. The scale originated from work to investigate which type of interaction in the first year of life led to which type of attachment behaviour and subsequently underwent reliability and validity investigations (Svanberg et al., 2013) using the Care-Index (Table 1) as the comparison variable because it has been extensively validated. There is a strong overall correlation between the PIIOS and the Care-Index maternal sensitivity scale (overall correlation coefficient $-0.86, p<0.001$ ), which has been shown to predict secure attachment. The internal consistency of the scale is good ( $\alpha=0.96$ ).

The final scale has 13 items, which assess dimensions along a three-point Likert scale using a narrative description for the observed behaviours, ranging from the most sensitively responsive to the least. The coder chooses the description, which most closely matches the interaction. Each item is scored as 0 (sensitively responsive/no interactional problems), 2 (some problems), or 4 (extensive problems).

There is a compelling and growing body of evidence (Center on the Developing Child, 2010) that the foundations for lifelong health and well-being are laid down in the first 1,000 days during pregnancy and up to a child's second birthday. Risk to a child can be identified and assessed much earlier than is current practice and as early as the first contact in pregnancy. We hypothesised that it might be possible to assess the parent-infant relationship earlier than 2 months, 

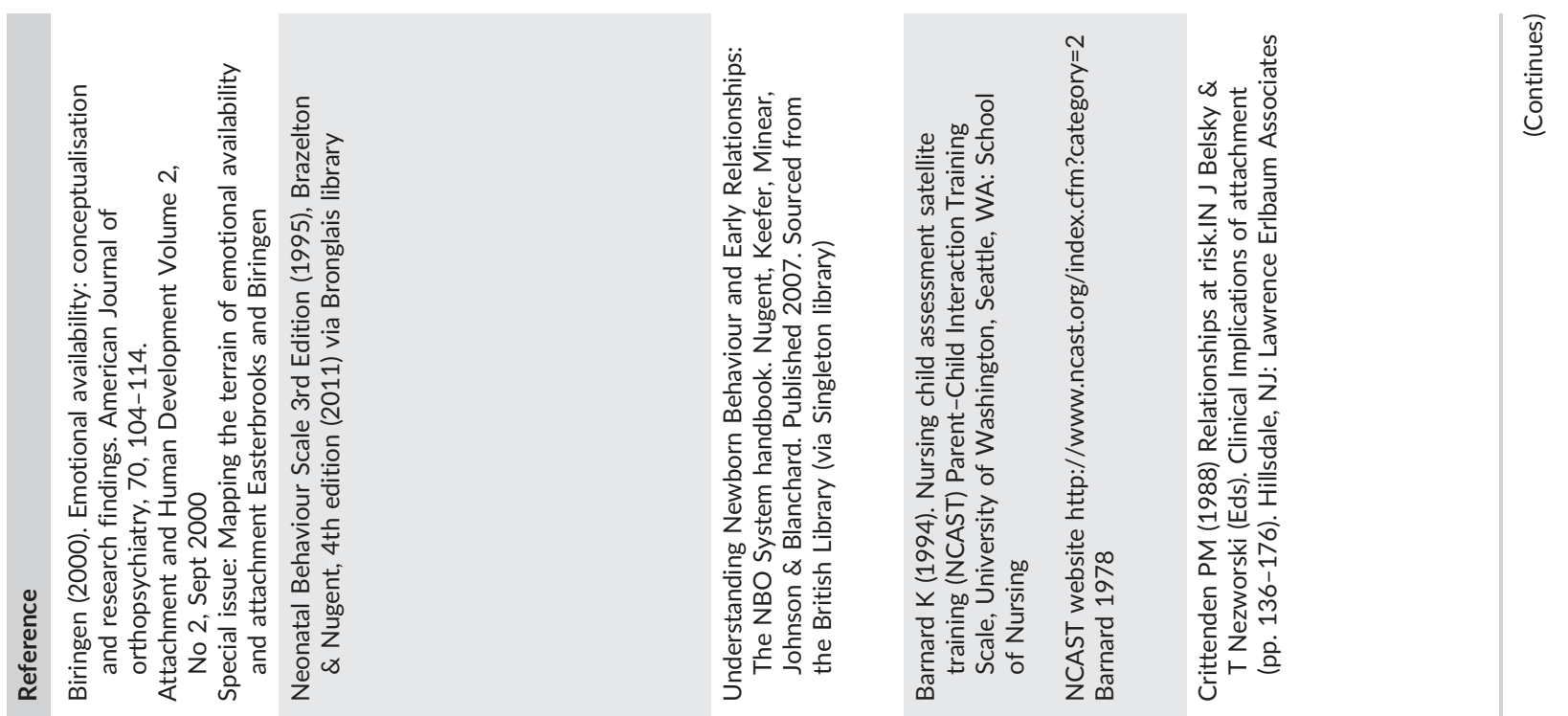

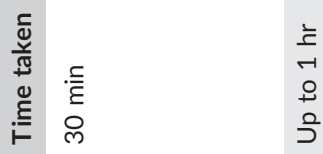
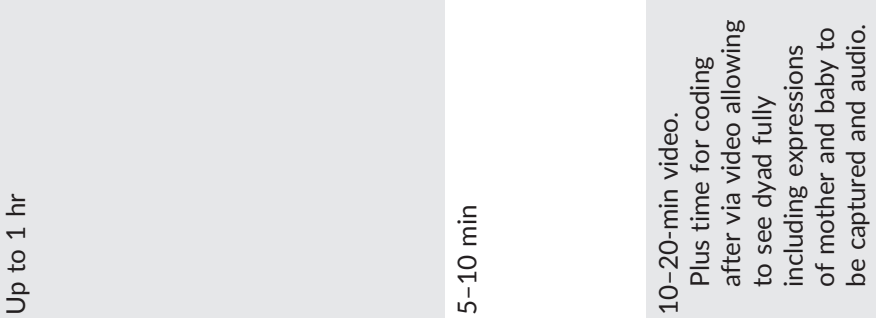

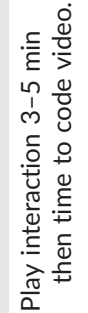

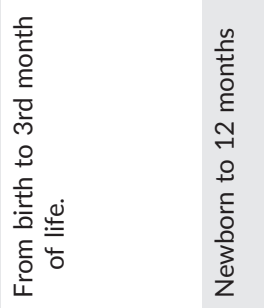

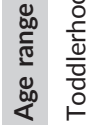

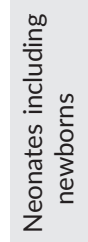

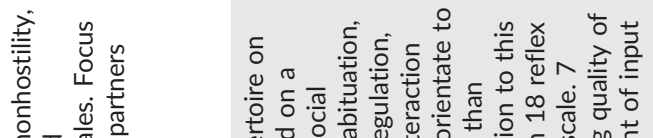

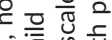

o0

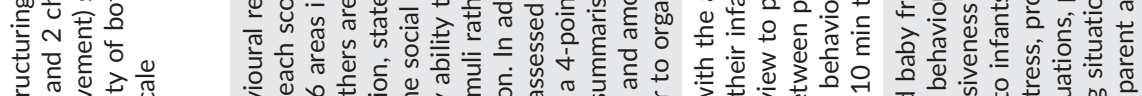

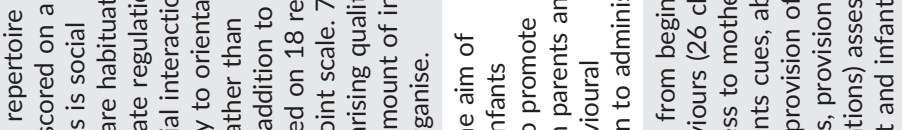

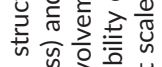

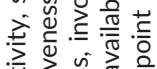

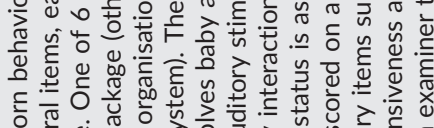

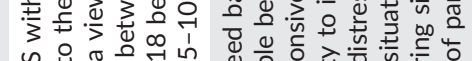

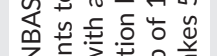

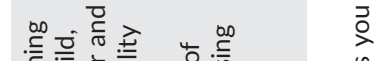

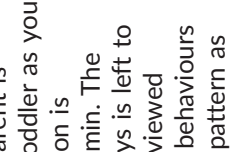

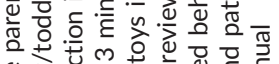

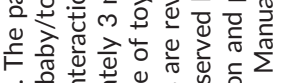

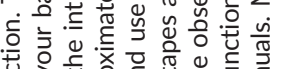

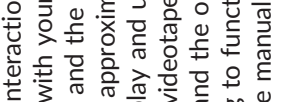

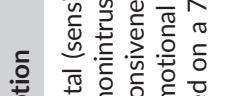

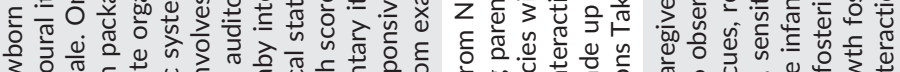

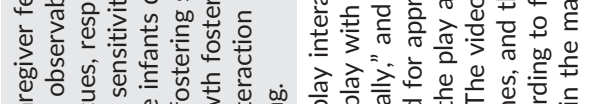

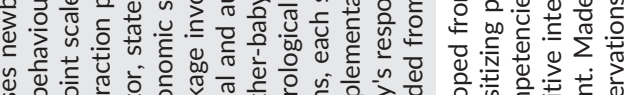
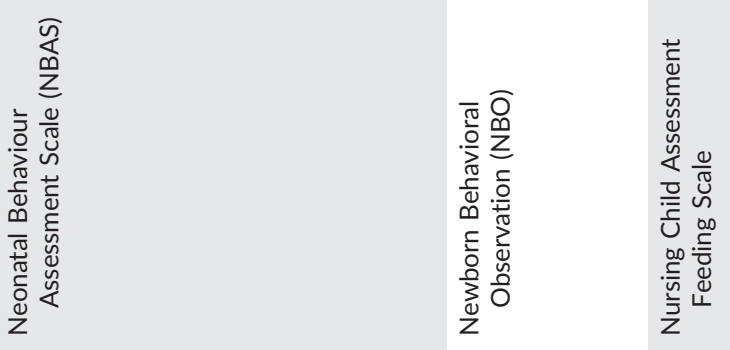


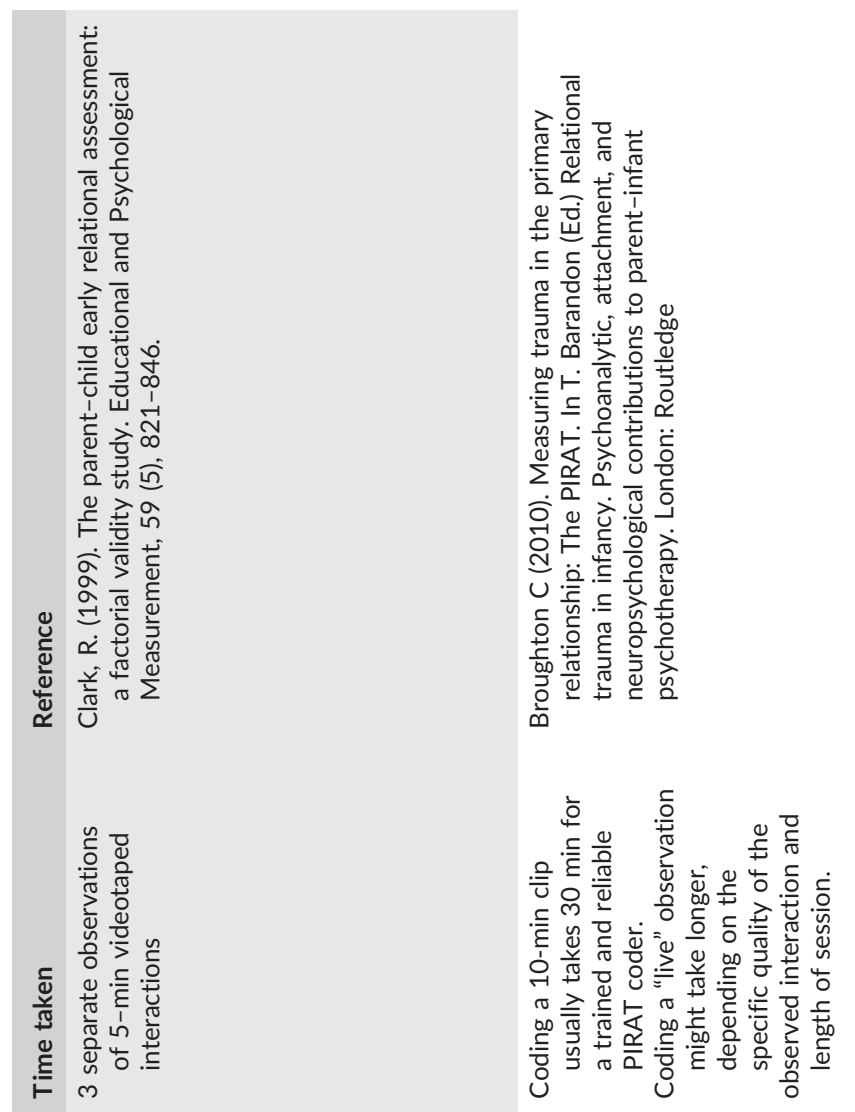

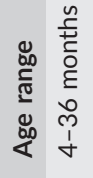

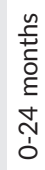
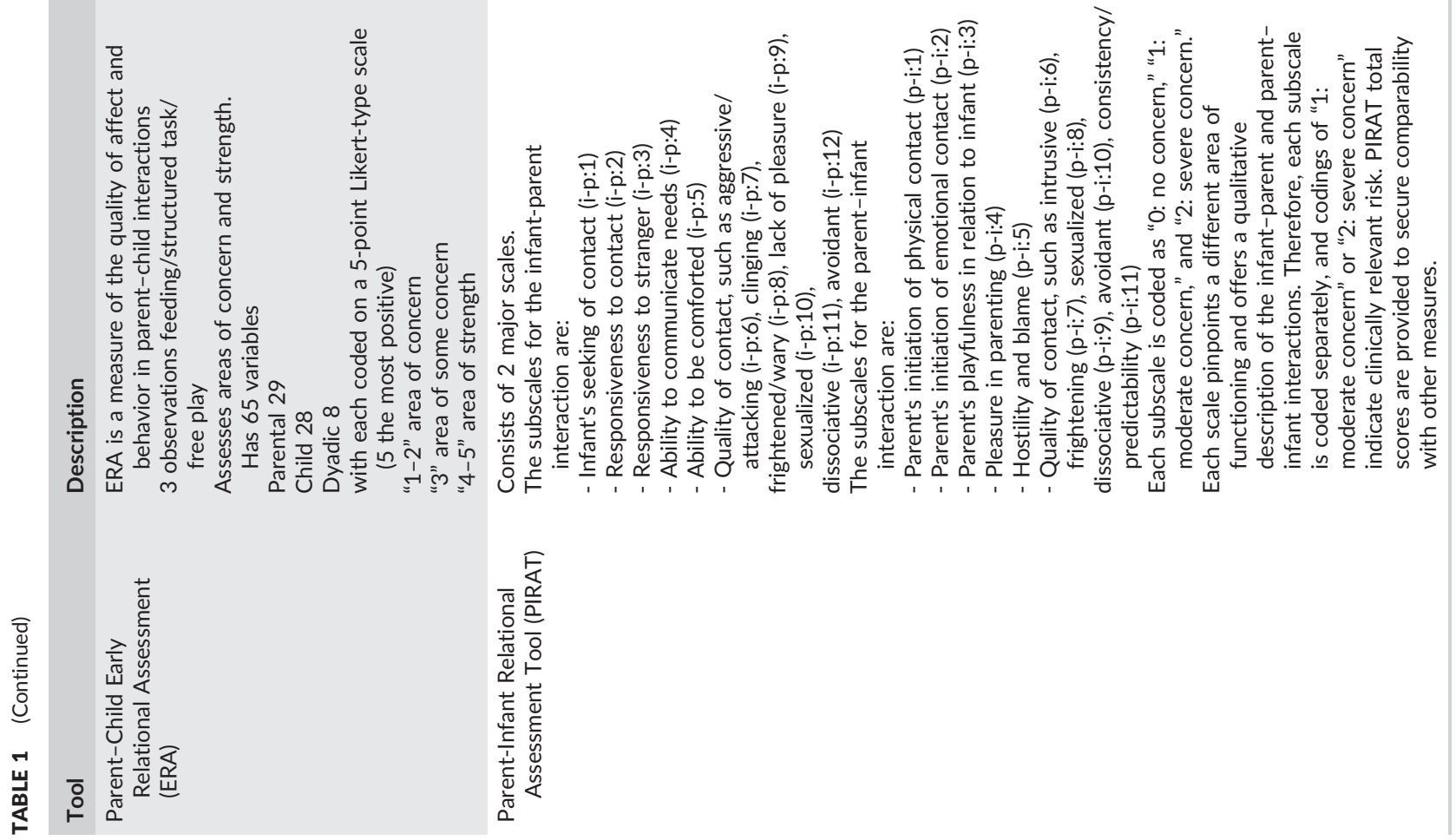


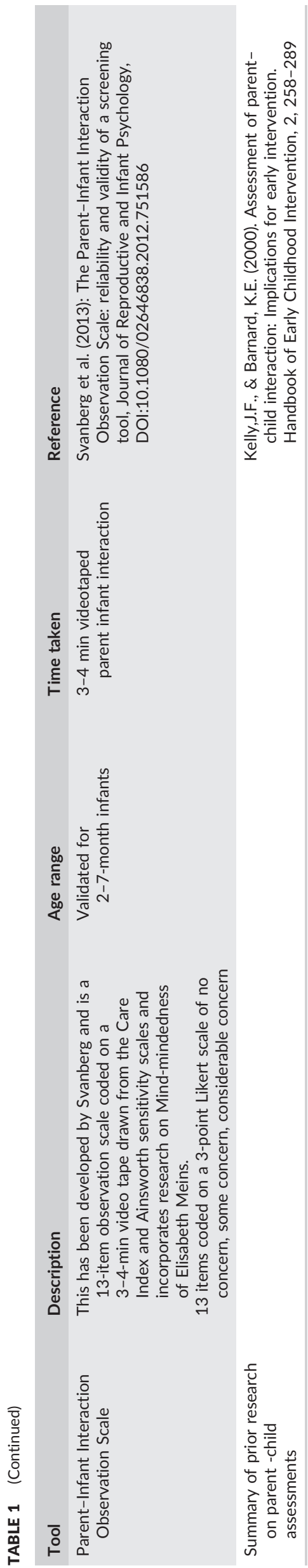

looking for potential vulnerability through application of a relatively simple screening tool (the PIIOS). Some support for this way of thinking exists. In a North American study (Vietze et al., 1980) of newborn behavioural and interactional characteristics as a predictor of later failure to thrive, successful observations of mother-infant pairs were conducted on the postnatal ward before discharge and within the first week of life. More recently, Wisconsin researchers (Gerstein, Poehlmann-Tynan, \& Clark, 2014) conducted a longitudinal study of mother child interactions to correlate observations in the neonatal intensive care unit to later parenting interactive quality at 24 months.

The aim of this study is to test the feasibility of using the PIIOS within the first 2 weeks of life, much earlier than its previous reliability testing at 2 to 7 months of age.

The study's objectives are to evaluate

- willingness of participants to be recruited

- attrition rates at Time 2

- willingness of midwives to inform potential participants

- number of eligible patients and practicality of recruitment strategy

- acceptability of the observation

- comparison of PIIOS scores at Times 1 and 2

- applicability of the coding scheme to recordings at Time 1

- response rates to questionnaires

- availability of data within health records

\section{2 | METHODOLOGY}

This single centre prospective feasibility study was conducted in the Cardiff and Vale University Health Board in Wales, the United Kingdom. The Welsh Index of Multiple Deprivation shows that defined small areas in Cardiff and the Vale of Glamorgan local authorities combined, are over represented in the Top $10 \%$ of the most deprived in Wales, accounting for 23\% of the population (Welsh Government, 2015). Cardiff local authority had the highest proportion of small areas in the most deprived $10 \%$ in Wales for child income deprivation (20.1\%) on recent measurement (Welsh Government, 2015). The study population included mothers of newborn infants, admitted antenatally for a hospital delivery. Recruitment commenced in July 2016. A sample size of an initial recruitment of 60 mother-infant pairs was based on a possible drop out rate of $50 \%$ for the second observation in the study. Home visits took place between July 2016 and November 2016. Prior to commencing the study ethical approval was obtained from the Wales Research Ethics Committee (REC reference 16/WA/0038).

Women admitted to the antenatal ward, largely for induction of labour, were invited to participate in the study. Exclusion criteria included infants admitted to the neonatal unit after birth. Women were not approached if infant admission was anticipated antenatally. This included preterm gestation less than 35 weeks and those with known significant structural anomalies. A discussion took place with the midwife on duty before talking to a woman. The common reason for being advised against approaching someone was significant pain making communication difficult. All women approached, once verbal consent obtained to discuss the research, were given an overview of the study 
and written information (Appendix A.1). Written consent was obtained for the researcher to check birth records to confirm the birth and for the woman to be contacted via telephone after the birth, to offer further participation in the study, using Consent form 1 (Appendix A.2). The register of births on labour ward was checked regularly to identify live births of women who had consented to being contacted. Once a live birth was confirmed, mothers were contacted after a minimum period of 2 days to confirm participation in the study and arrange a suitable time for the home visit to record the parent-infant interaction.

Three researchers, all practicing paediatric doctors at registrar or consultant level, undertook the home visits. The Time 1 recordings were undertaken within 2 weeks of birth and Time 2 between 8 to 10 weeks of age. During each visit, an overview of the study procedures was given and written consent to proceed obtained using Consent form 2, (Appendix A.3). At the Time 1 visit, a semistructured interview (Appendix A.4) was undertaken with the mother and father if present, to obtain demographic data and additional information regarding family income and family structure. At each visit, a recording of 3-min duration was obtained of the mother and infant dyad using a handheld camcorder. The recordings aimed to include both the mother's and baby's faces to enable coders to adequately visualise subtle movements, facial expressions, and vocalisations. Mothers were advised to "talk and play with your baby as you normally would" prior to the recording. At the Time 2 visit, a significant events questionnaire (Appendix A.5) was completed to attempt to capture life events that might have impacted, the parent infant relationship in the intervening period. A $£ 20$ shopping voucher was given to each mother at the second visit.

Recordings were uploaded to a password-protected laptop and erased from the camcorder memory. Recordings were scored at a later date according to the 13 PIIOS items focusing specifically on the interactive behaviour of the observed dyad. A health visitor, who had been trained in the use of the PIIOS, coded each recording. The interrater reliability (ICC) for PIIOS coding is established $(0.94,95 \% \mathrm{Cl}[0.93$, 0.95]) from previous testing.

\section{3 | RESULTS}

The mother's demographic and pregnancy details are presented in Tables $2 \mathrm{~A}$ and $2 \mathrm{~B}$.

The infants' demographic details are presented in Table 3.

Objectives of the feasibility study:

\section{Willingness of participants to be recruited}

Most women were willing for the researcher to sit and discuss the study and went on to sign Consent form 1. Of the 60 women who consented to be contacted post-delivery, 30 participated in the study at Time 1.

\section{Willingness of midwives to inform potential participants}

In response to comments made during consultation on the protocol (ethics committee and consultant research midwives), the approach was modified to one where the women were informed about the study by a researcher on the team. The midwives' prior knowledge of women on the induction ward was highly valued by the researcher in identifying which women might be more or less suitable for inclusion.

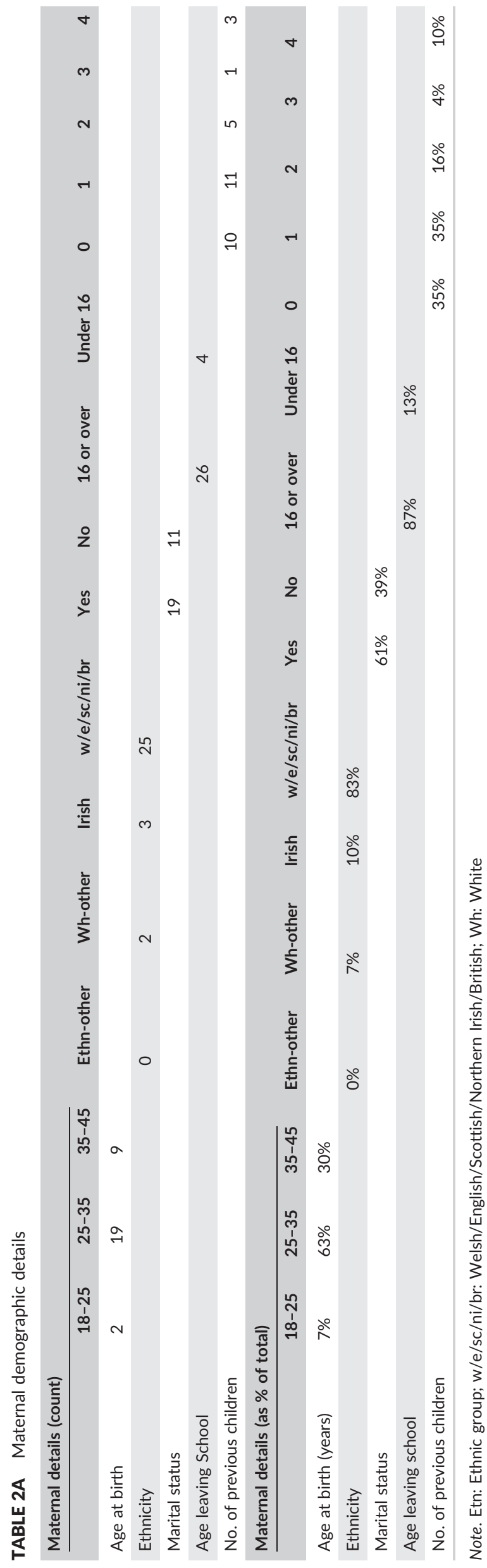


TABLE 2B Maternal pregnancy

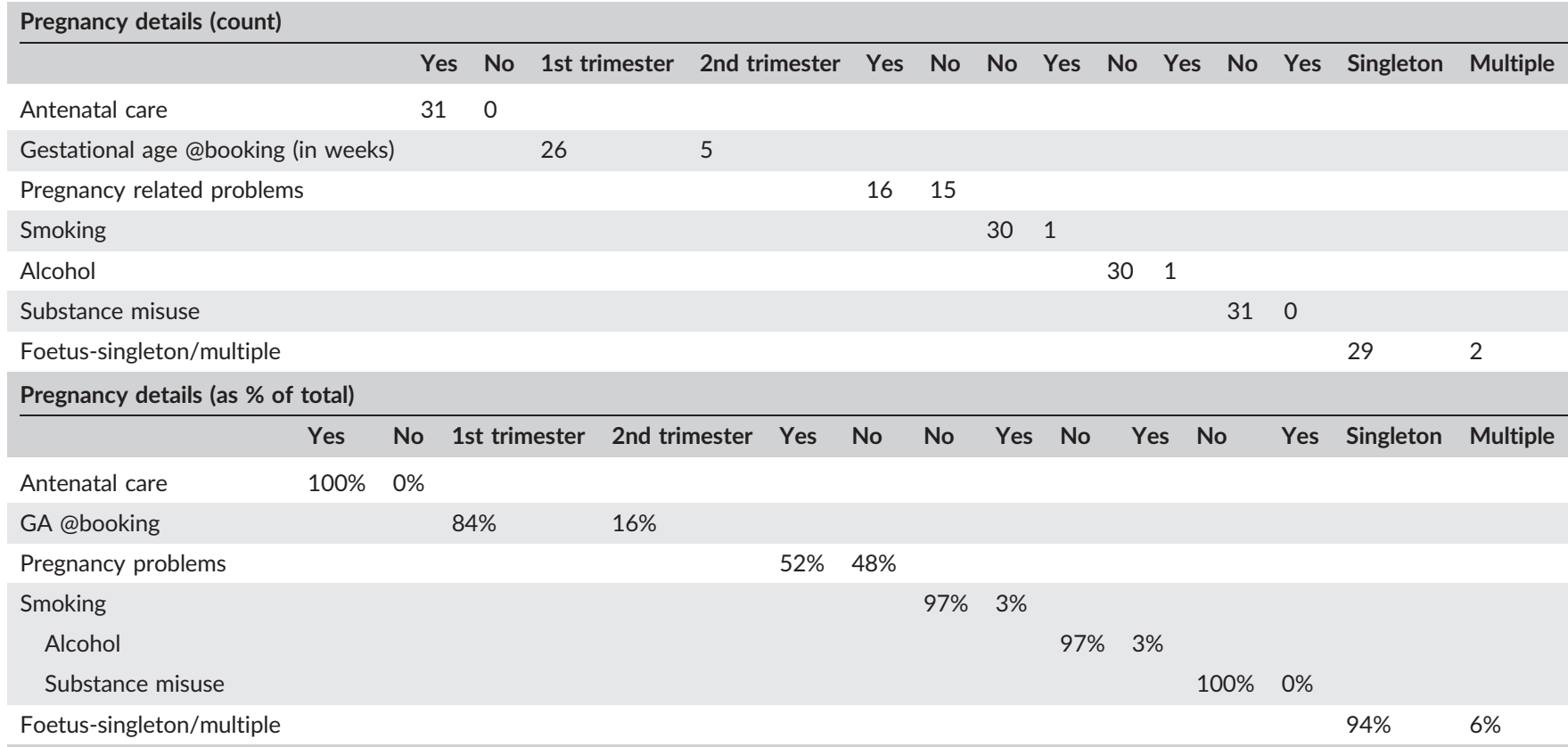

TABLE 3 Infant details

\begin{tabular}{|c|c|c|c|c|c|c|c|c|c|c|c|c|c|c|}
\hline \multicolumn{15}{|l|}{ Infant details (count) } \\
\hline & Male & Female & Term & Preterm & $\begin{array}{l}\text { C-section } \\
\text { elective }\end{array}$ & $\begin{array}{l}\text { C-section } \\
\text { emergency }\end{array}$ & Instrumental & SVD & None & PPH & PROM & $\begin{array}{l}\text { Retainec } \\
\text { placenta }\end{array}$ & No & Yes \\
\hline Gender & 17 & 14 & & & & & & & & & & & & \\
\hline Gestational age @birth & & & 31 & 0 & & & & & & & & & & \\
\hline Mode of delivery & & & & & 3 & 2 & 6 & 20 & & & & & & \\
\hline Complications@birth & & & & & & & & & 25 & 3 & 2 & 1 & & \\
\hline \multicolumn{15}{|c|}{ Infant details (as \% of total) } \\
\hline & Male & Female & Term & Preterm & $\begin{array}{l}\text { C-section } \\
\text { elective }\end{array}$ & $\begin{array}{l}\text { C-section } \\
\text { emergency }\end{array}$ & Instrumental & SVD & None & PPH & PROM & $\begin{array}{l}\text { Retained } \\
\text { placenta }\end{array}$ & No & Yes \\
\hline Gender & $55 \%$ & $45 \%$ & & & & & & & & & & & & \\
\hline GA @birth & & & $100 \%$ & $0 \%$ & & & & & & & & & & \\
\hline
\end{tabular}

Note. CS elective: elective caesarian section; CS emerg: emergency caesarian section; Instrument: instrumental delivery (forceps/ventouse); SVD: spontanoeous vaginal delivery; PPH: post partum haemorrhage; PROM: prolonged rupture of membranes; R Placenta: retained palcenta

3. Number of eligible participants and the practicality of the recruitment strategy (to include attrition rate at Time 2)

One of the team researchers worked in the hospital neonatal unit during the recruitment phase of the study. She was known to labour ward staff and was able to visit daily to discuss the study with potential participants. She regularly checked the birth notification system to ascertain the outcome of mothers who had given birth to live infants and who had consented to be contacted.

Sixty women expressed an interest and gave consent to be contacted post-delivery of their baby. Fifty-seven women were eligible for inclusion, three were excluded because of infant admission to the neonatal unit. Twenty-six women declined further involvement or were unavailable when approached by the researcher in the postnatal period. Thirty women subsequently agreed to participate at Time 1 and at Time 2. However, only 28 were visited and recorded at Time 2 because two women were unavailable during the time frame 8 to 12 weeks (one was on holiday, and the other was not available on any of the dates offered).

4. Acceptability of the observation and response rate to the questionnaire

Women found the observation quite acceptable and after a brief time settled in to being recorded without seeming to be too selfconscious. Some initial issues with regard to recording quality, relating 
to inexperience of the camcorder operator, impacted on the clarity of subsequent coding.

Difficulties included:

- Researcher talking over the recording

- Baby asleep throughout the observation

- TV or radio on affecting quality of recording including interactive comments between the dyad

- Video recorder failed to record on one occasion

- Noise interference from sibling, other relative, or family dog

- Mother's face hidden at times

- Baby distracted by the researcher recording at Time 2

There was $100 \%$ response rate for questionnaire completion at the visits (T1 and T2). Following a modification of the questionnaire post ethics committee comments, data were not retrieved from health records, as this was not required for the feasibility study.

\section{- Comparison of PIIOS scores at T1 and T2}

Most dyads scored within the "No Concern" range with similar results at T1 and T2. In five dyads, the score was different between T1 and T2, three were coded "No Concerns" at T1 with "Some Concern" at T2, and one was coded Some Concern at T1 but No Concern at T2. Another dyad was coded No Concern at T1, but the coder could not code at $\mathrm{T} 2$ because the baby was asleep.

The senior researcher reviewed all videos. There were no safeguarding concerns. In the cases coded as Some Concern at T2, it would be usual clinical practice to repeat the video as there is no indication that this implies a pathological relationship.

- Applicability of the coding to recordings at T1

With an awake baby PIIOS Questions 1, 4, 5, 6, 7, 8, 9, 10, 11, 13 (Appendix A.1) could be easily scored. At T1, the following PIIOS questions were difficult to score:

Item 2 developmentally, a baby may not be able to control their head sufficiently to avoid an intrusive mother.

Item 3 vocalisations are not expected at this stage of development. Item 12 responsive turn taking is developmentally not expected at this age.

Overall, the coder stated that it is possible to use PIIOS at this early stage even though some of the questions may need to be modified or removed from the scoring system.

\section{4 | DISCUSSION}

Observational measures have been used before in prospective longitudinal studies starting in early infancy (Fiese, Poehlmann, Irwin, Gordon, \& Curry-Bleggi, 2001; Gerstein et al., 2014) but took longer in terms of coding the observation (Gerstein et al., 2014), or the infants were older at the time of the observation (Fiese et al., 2001 mean age 6 months). To our knowledge, this is the first time observation of mother-infant interactions using a brief recording has been carried out so early in the postnatal period. Our study provides promising information to pursue further groundbreaking research on the reliability and validity of the screening tool at this age. Women in this study found it acceptable to be visited at home within the first 2 weeks after delivery, share information about the pregnancy and birth, and to participate in an audiovisual recording of them interacting with their babies. Although the design of the study did not set out to identify which factors in the interaction might identify vulnerability, it was nevertheless possible to score the observation in 10 of the 13 interactional PIIOS dimensions, in an awake baby. Thirty-five percent of babies in our study were asleep throughout the recording at the first home visit. Most of these 10 scores are dependent on the mother's behaviour towards the baby but not exclusively. Item 4 (affective engagement and synchrony), Item 5 (warmth and affection), Item 11 (empathic understanding), and Item 13 require observation of the baby's behaviour and the mothers behaviour in relation and context, with the subsequent score being dependent on both aspects. Only three items were unavailable for scoring because they were developmentally inappropriate (eye contact, vocalisations, and responsive turn taking).

Our understanding of the relationship between the environment and the neurobiological development of the human brain has grown vastly over recent decades (National Scientific Council on the Developing Child, 2004). Contrary to previous popular belief, the genes inherited from one's parents do not set a child's future development in stone. In fact, environmental influences affect whether and how genes are expressed, and the caregiving relationship between mother and baby has a fundamental role in this biological process (National Scientific Council on the Developing Child, 2010).

The costs associated with negative and inappropriate parent-child interactions have been widely documented, (Schore, 2001). Chronic omission of a nurturing parent-child relationship to promote emotional growth and development constitutes neglect, and in extreme cases, emotional abuse with long-term impact on the developing infant brain increasingly understood (Shipman \& Zeman, 2001). Child abuse and neglect encompass several adverse childhood experiences (ACEs) and persistent exposure to danger sensitises the hyper-arousal response, so that this is subsequently triggered in more benign situations. Three of the 10 commonly listed ACEs, parental substance or alcohol misuse, domestic abuse, and parental mental ill health, were the most frequently recorded parenting capacity factors for about a quarter of children receiving care and support in Wales, United Kingdom, in 2017 (Welsh Government, 2018).

Understanding how ACEs affect individuals' health and behaviour across the life course has transformed thinking in Public Health Policy across the United Kingdom recently particularly in Wales (Welsh Government, 2017). Recognisng that not everyone who suffers ACEs goes on to have the same harmful outcomes, the policy focus is moving towards building resilience (Welsh Government, 2017).

\section{5 | LIMITATIONS}

We acknowledge the limitation of the lack of purposive sampling, which resulted in our sample coming predominantly from higher socio-economic groups and not representative of the diversity of the local population. Very few high-risk vulnerable women with more 
chaotic lifestyles were captured so we cannot comment on the acceptability of the tool in this group.

The PIIOS tool has some limitations. It is less sensitive at differentiating "sensitive enough dyads" (in terms of their parental responsiveness) from each other with a tendency to group the "minimal risk" and "good enough" together in one group. This factor would need to be taken into account in any further research based on the outcome of the feasibility study.

\section{6 | CONCLUSIONS}

The positive findings are very promising. They can inform further exploration of an observation tool within an early intervention programme using a universal approach to identify high risk dyads for targeted support. The results support the recommendation that a trial and test of a modified scoring system (based on the PIIOS) be developed for a future study using a larger sample size containing high risk dyads. Further research will be required to assess whether such an approach can reliably produce a consistent valid screening tool to assess parental sensitive responsiveness and resilience promoting behaviours at this early stage of life. Furthermore specificity of the tool, to establish the link to later child maltreatment, is essential to avoid false positive identification following these early observations.

\section{FINANCIAL INTEREST}

None of the authors have any financial interests to disclose.

\section{CONFLICT OF INTERESTS}

None of the authors have any conflict of interests.

\section{ORCID}

Aideen Naughton (10) https://orcid.org/0000-0003-1631-5923

\section{REFERENCES}

Ainsworth, M., Blehar, M., Waters, E., \& Wall, S. (1978). Patterns of attachment: Assessed in the strange situation and at home. Hillsdale, $\mathrm{NJ}$ : Erlbaum

Appleton, J. V., Harris, M., \& Oates, J. (2010). A pilot study to evaluate the accuracy of health visitor assessments of the quality of mother-infant interactions. London: Burdett Trust for Nursing.

Balbernie, R. (2001). Circuits and circumstances: The neurobiological consequences of early relationship experiences and how they shape later behaviour. Journal of Child Psychotherapy, 27(3), 237-255. https://doi.org/10.1080/00754170110087531

Balbernie, R. (2013). Poised to connect: How early relationships affect brain development. International Journal of Birth and Parent Education, 5(1), 26-28.

Barnard, K. (1994). Nursing child assessment satellite training (NCAST)Parent-Child Interaction Training Scale. University of Washington, Seattle, WA: School of Nursing NCAST website http://www.ncast.org/index.cfm?category= 2Barnard 1978

Biringen, Z. (2000). Emotional availability: conceptualisation and research findings. American Journal of Orthopsychiatry, 70, 104-114. https://doi.org/10.1037/h0087711

Bowlby, J. (1982). Attachment and loss: Retrospect and prospect. American Journal of Orthopsychiatry, 52(4), 243-256.
Brazelton, T. B., \& Nugent, J. K. (2011). Neonatal Behavior Assessment Scale (4th Ed). London: MacKeith Press ISBN 978-1-907655-03-6.

Broughton, C. (2010). Measuring trauma in the primary relationship: The Parent-Infant Relational Assessment Tool (PIRAT). In T. Barandon (Ed.), Relational trauma in infancy. Psychoanalytic, attachment and neuropsychological contributions to parent-infant psychotherapy. London: Routledge.

Center on the Developing Child (2010). The foundations of lifelong health are built in early childhood. Retrieved from www. developingchild.harvard.edu. Accessed 16 April 2018.

Clark, R. (1999). The parent-child early relational assessment: a factorial validity study. Educational and Psychological Measurement, 59(5), 821-846.

Crittenden, P. M., \& Bonvilian, J. D. (1984). The relationship between maternal risk status and maternal sensitivity. American Journal of Orthopsychiatry, 54(2), 250-262. https://doi.org/10.1111/j.1939-0025.1984.tb01492.x

Crittenden, P. M. (1988). Relationships at risk. In J. Belsky \& T. Nezworski (Eds.), Clinical Implications of attachment (pp. 136-176). Hillsdale, NJ: Lawrence Erlbaum Associates.

Department of Health (2009). Healthy child programme: Pregnancy and the first five years of life. London: Stationery office.

Fiese, B. H., Poehlmann, J., Irwin, M., Gordon, M., \& Curry-Bleggi, E. (2001). A pediatric screening instrument to detect problematic infant-parent interactions: Initial reliability and validity in a sample of high-and low-risk infants. Infant Mental Health Journal, 22(4), 463-478. https://doi.org/ 10.1002/imhj.1011

Gerstein, E. D., Poehlmann-Tynan, J., \& Clark, R. (2014). Mother-child interactions in the NICU: Relevance and implications for later parenting. Journal of Pediatric Psychology, 40(1), 33-44. https://doi.org/10.1093/ jpepsy/jsu064

Kelly, J. F., \& Barnard, K. E. (2000). Assessment of parent-child interaction: Implications for early intervention. Handbook of Early Childhood Intervention, 2, 258-289.

Maguire, S. A., Williams, B., Naughton, A. M., Cowley, L. E., Tempest, V., Mann, M. K., ... Kemp, A. M. (2015 Sep). A systematic review of the emotional, behavioural and cognitive features exhibited by school-aged children experiencing neglect or emotional abuse. Child: Care, Health and Development, 41(5), 641-653.

Meins, E., Fernyhough, C., Fradley, E., \& Tuckey, M. (2001). Rethinking maternal sensitivity: Mothers'comments on infants'mental processes predict security of attachment at 12 months. Journal of Child Psychology and Psychiatry, and Allied Disciplines, 42(5), 637-648.

Meins, E., Fernyhough, C., Wainright, R., Clark-Carter, D., \& Das Gupta, M. (2003). Pathways to understanding the mind: Construct validity and predictive validity of maternal mind-mindness. Child Development, 74(4), 1194-1211. https://doi.org/10.1111/1467-8624.00601

National Scientific Council on the Developing Child (2004). Children's Emotional Development Is Built into the Architecture of Their Brains: Working Paper No. 2. Retrieved from https://www.developingchild. harvard.edu. Accessed 16 April 2018.

National Scientific Council on the Developing Child (2010). Early experiences can alter gene expression and affect long-term development: Working Paper No. 10. Retrieved from https://www.developingchild.harvard.edu. Accessed 16 April 2018.

Naughton, A. M., Maguire, S. M., Mann, M. K., Lumb, R. C., Tempest, V., Gracias, S., \& Kemp, A. M. (2013). Emotional, behavioural and developmental features indicative of neglect or emotional abuse in preschool children: A systematic review. JAMA Pediatrics, 167(80), 769-775. https://doi.org/ 10.1001/jamapediatrics.2013.192

Schore, A. N. (1994). Affect regulation and the origin of the self: The neurobiology of emotional development. New Jersey: Erlbaum.

Schore, A. N. (2001). Effects of early relational trauma on right brain development, affect regulation, and infant mental health. Infant Mental Health Journal, 22(1-2), 201-269. https://doi.org/10.1002/ 1097-0355(200101/04)22:1<201::AID-IMHJ8>3.0.CO;2-9 
Shipman, K. L., \& Zeman, J. (2001). Socialisation of children's emotion regulation in mother-child dyads: A developmental psychopathology perspective. Development and Psychopathology, 13(2), 317-336.

Svanberg, P. O., Barlow, J., \& Tigbe, W. (2013). The Parent-Infant Interaction Observation Scale: Reliability and validity of a screening tool. Journal of Reproductive and Infant Psychology, 31(1), 5-14. https://doi.org/10.1080/02646838.2012.751586

Vietze, P. M., Falsey, S., O'Connor, S., Sander, H., Sherrod, K., \& Altemeier, W. A. (1980). Newborn behavioral and interactional characteristics of nonorganic failure-to-thrive infants. In I. Martin, T. Field, S. Goldberg, D. Stern, \& A. Miller-Sostek (Eds.), High-risk infants and children: Adult and peer interactions. New York: Academic Press.

Welsh Government (2015). Welsh Index of Multiple Deprivation (WIMD) 2015; 2015. Retrieved from https://statswales.gov.wales/Catalogue/ Community-Safety-and-Social-Inclusion/Welsh-Index-of-MultipleDeprivation/WIMD-2014/wimd2014localauthorityanalysis. Accessed 16 April 2018.

Welsh Government (2016). Healthy Child Wales Programme. Retrieved from http://gov.wales/docs/dhss/publications/160926healthy-childrenen.pdf. Accessed 16 April 2018.

Welsh Government (2017). Prosperity for all: The National Strategy; 2017. https://beta.gov.wales/prosperity-all-national-strategy. Accessed 16 April 2018.

Welsh Government (2018). Wales children receiving care and support census 2017, 8 March 2018. Retrieved from http://statswales.gov.wales/ Catalogue/Health-and-Social-Care/Social-Services/Childrens-Services/children-receiving-care-and-support/. Accessed 16 April 2018.

How to cite this article: Naughton A, Perkins L, McMinn B, Kemp A. Using an observation tool (Parent-Infant Interaction Observation Scale) to assess parent-infant interaction in the first 2 weeks of life: A feasibility study. Child Care Health Dev. 2019;1-15. https://doi.org/10.1111/cch.12637

\section{APPENDIX A \\ APPENDICES}

1. Parent-Infant Interaction Observation Scale (PIIOS): 13 interactional dimensions

2. Patient information leaflet

3. Consent form 1 and Consent form 2

4. Semistructured interview-mother and infant

5. Significant events questionnaire

\section{A.1 | Appendix 1}

PIIOS: 13 interactional dimensions.

1. Infant positioning

2. Eye contact

3. Vocalisations

4. Affective engagement and synchrony

5. Warmth and affection

6. Holding and handling

7. Verbal commenting; mind-mindedness

8. Attunement to distress
9. Bodily intrusiveness

10. Expressed expectations about the baby

11. Empathic understanding

12. Responsive turn taking

13. Baby's self-soothing strategies

\section{A.2 | Appendix 2}

Parent information sheet

Principal investigator: Dr. Aideen Naughton,

Public Health Wales

Study title: Early observation of vulnerability in parent-infant interaction

Thank you for reading this leaflet

This leaflet gives you information about a research study looking at how mothers and babies interact with each other. We would like to invite you and your baby to take part in this study. We want to help you to understand why the research is being done and what is involved before you make your decision. Please take time to read the leaflet carefully and discuss it with others if you wish. If anything is unclear or you are unsure and would like more information, please ask us.

Part 1 of this leaflet tells you the purpose of this study and what happens if you decide to take part.

Part 2 gives you more information about the study.

\section{Part 1}

1.1. What is the purpose of this study?

We know that parent baby interaction has an effect on a baby's health and development as she grows up. However, there is not much research on how best to assess parents interacting with their new born babies. We want to test a tool for observing parents and their babies to see if it is possible to use it in the first 2 weeks of life.

\subsection{Why have I been chosen?}

We are asking mothers of babies born at University Hospital of Wales, who live in Cardiff or the Vale area if they would like to take part in our study.

Do I have to take part?

No. It is your choice. If you do choose to take part, you can change your mind at any time without giving a reason. The research team is not part of the normal NHS healthcare team who will be looking after you and your baby. Our assessments and appointments with you and your baby will be in addition to your normal postnatal care and will not affect this care at all.

\subsection{What will happen if I take part?}

We will phone you to arrange to visit you in your home in the first 2 weeks after your baby's birth. At this visit, we will ask you to give us information about you and your family circumstances and to observe you talking and playing with your baby. We will also ask your permission to look at health records for you and your baby. 
The observation will be recorded using a camcorder and lasts about $3 \mathrm{~min}$. It is important this takes place in the first 2 weeks of life, as we want to understand very early parent baby interactions. We will make an appointment with you for a second session before we leave. This session will take place when your baby is about 8 to 10 weeks. It will be at your home or at a local clinic if this is easier for you. We will phone you 1 week before the appointment to remind you about it. When we meet, we will ask you some questions to understand what has been happening in your life since the first home visit. We will then repeat the recording of you talking and playing with your baby.

\subsection{What are the risks of taking part?}

We do not expect any risks to you or to your baby by taking part in this study. We will observe you and your baby at each session and make a digital recording. This is our assessment, and it will be repeated at the follow-up appointment. No extra tests will be carried out on your baby as part of this study. The findings of the assessments will only be used as part of the research study and will not be shared with any other agency. *

\subsection{What are the benefits of taking part?}

We hope that the information from this study will help midwives and health visitors identify families who need additional support soon after their babies' birth. As this is an observational study, we are not expecting any direct benefit for your baby. You will be given a $£ 20$ shopping voucher to thank you for taking part in the study.

\subsection{What if there was a problem?}

You have a right to raise your concerns about any possible distress you may have suffered or if you wish to complain about how you have been treated. Information on how to do this is given in Part 2.

\subsection{Will my involvement be kept confidential?}

Yes. All information about you and your baby will be handled in confidence in line with ethical and legal practice. ${ }^{*}$ The details are included in Part 2.

If the information in Part 1 has interested you and you are considering becoming involved, please read the additional information in Part 2 before making your decision.

\section{Part 2}

2.1. What will happen if I do not want to carry on with the study?

If you decide to withdraw from the study you are free to do so at any time. We would like to use any information that we have collected up to your withdrawal. However, if you do not want us to use any of your material, these documents will be destroyed confidentially in line with your wishes.

\subsection{What if there is a problem?}

We do not expect there to be any problems for you or your baby from taking part in this study. If you or your baby seems unwell or if you have worries about your baby or about your own health, we will talk with your midwife, health visitor, or GP to get you the right help. We will do this with your consent.

If you are worried about any part of this study, you can talk to the researchers who will do their best to answer your questions. Please contact 01495332225 to contact Dr. Aideen Naughton.

\subsection{What if I want to make a complaint?}

You have the right to raise a concern if you are unhappy about any part of the study or the behaviour of the researchers.

You do this by contacting the concerns team:

\begin{tabular}{ll} 
Phone: & (029) 20227744 \\
\hline Email: & publichealthwales.handlingconcerns@wales.nhs.uk \\
Post: & Rhiannon Beaumont Wood \\
& Director of Nursing \\
& 14 Cathedral Road, \\
& Cardiff, \\
& CF11 9LJ
\end{tabular}

\subsection{What will happen to the results of the study?}

We will publish the results of this study in medical or scientific journals and present the findings at professional meetings. You and your baby's name and details are not revealed at any stage. The results of the research will not be directly shared with you but should you be interested the results will be made available to you.

\subsection{Will my taking part be kept confidential?}

All information that is collected about you and your baby during the course of this research will be kept strictly confidential. ${ }^{*}$ We will do this by limiting who sees the data to a small research team. We will also give each baby a number and use this to identify any information collected. None of your personal information will be linked to the results or stored on computers. Your consent forms, with your name on them, will be stored in a locked safe. When giving your consent, you will be asked if we can keep your data for future research purposes only. If you say no, then all your information will be destroyed after the research project is finished.

\subsection{Who is paying for the study?}

The National Institute for Social Care and Health Research is funding this study.

Dr. Aideen Naughton clinical research fellow at Cardiff University and Public Health Wales will be carrying out this study.

\subsection{Who has reviewed the study?}

All research in the NHS is looked at by an independent group of people called a Research Ethics Committee, to protect you and your child's safety, rights, well-being, and dignity. The Wales REC 3 committee and the Research and Development committees in Public Health Wales and Cardiff \& Vale University Health Board have reviewed this study. 
2.8. Who can I contact for further information?

You may contact Dr. Aideen Naughton on 01495332225.

*In the unlikely event that child or adult protection concerns came to light during our researchers' contact with you and your baby, we have a duty to report this to appropriate agencies. Any such concerns will be shared with you at the time, and we will fully explain the procedure that will be followed if this happens.

May we thank you once again for taking time to think about getting involved with this study.

\section{A.3 | Appendix 3: Consent forms I and II}

Identification number for this study:

Consent form I (Consent to be contacted)

Early observation of vulnerability in parent-infant interaction

Name of researchers: Dr. Aideen Naughton Public Heath Wales and Professor Alison Kemp, Cochrane Institute of Primary Care and Public Health, Cardiff University.

Identification number for this study:

Consent form II

1. I agree to my details being shared with the research team so that I may be contacted in relation to this study.

Please initial

box

2. I agree to the birth of my baby being notified to the research team

3. I have been given the Parent Information Sheet dated 01/03/2016

Name of Participant

Date
Signature

Name of Researcher taking consent

Date

Signature

Copies: 1 for patient, 1 for researcher, 1 for Midwifery File. 
Early observation of vulnerability in parent-infant interaction

Name of researchers: Dr. Aideen Naughton Public Health Wales

and Professor Alison

Kemp, Cochrane Institute of Primary Care and Public Health, Cardiff University.

Please

1. I confirm that I have read and understand the information sheet dated $01 / 03 / 2016$ for the above study and have had the opportunity to ask questions. I understand that

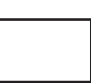

if there are concerns about my or my baby's welfare that this will be reported to the appropriate agencies.

2. I understand that my participation and that of my baby is voluntary and that I am free to withdraw my permission at any time, without giving any reason and without my child's medical care or legal rights being affected.

3. I give permission for the research individuals to have access to my and my baby's medical records to extract information on maternal age, education, family income, number of children, number of previous pregnancies, ethnicity, marital status, my recent pregnancy and the birth and that this information will be stored on a protected computer.

4. I give my permission for two video recordings (one within 2 weeks of birth, the second at 8-10 weeks) to be made of my baby and me in which our faces can be seen and that these videos are used for research purposes.

5. I give permission to data from the recordings being kept for future research purposes.

6. I agree that a study doctor can visit my home to conduct the video recordings

7. I agree to my baby and I to take part in the study 


\section{A.4 | Appendix 4}

Semistructured interview-parent

Early observation of vulnerability in parent-infant interaction

Maternal questionnaire

Case No.

1. Age (at birth of this baby)

2. Ethnic group?

Choose one option that best describes your ethnic group or background.

White

1. Welsh/English/Scottish/Northern Irish/British

2. Irish

3. Gypsy or Irish traveller

4. Any other White background, please describe

Mixed/multiple ethnic groups

5. White and BlackCaribbean

6. White and Black African

7. White and Asian

8. Any other mixed/multiple ethnic background please describe

Asian/Asian British

9. Indian

10. Pakistani

11. Bangladeshi

12. Chinese

13. Any other Asian background, please describe

Black/African/Caribbean/Black British

14. African

15. Caribbean

16. Any other Black/African/Caribbean background please describe

Other ethnic group

17. Arab

18. Any other ethnic group, please describe

(*Ref: office for national statisticshttp://www.ons.gov.uk/ons/guidemethod/measuring-equality/equality/ethnic-nat-identity-religion/ index.html)
1. Are you married? Yes $\circ$ no $\circ$

2. Are you in a relationship? Yes $\circ$ no $\circ$

Occupation, please state

Are you unemployed? Yes $\circ$ no $\circ$

3. Did you leave school before age 16 years? Yes $\circ$ no $\circ$

4. How many other children do you have? None $12345>5$

Questionnaire-infant (for semistructured interview)

Early observation of vulnerability in parent-infant interaction. Infant questionnaire ${ }^{1}$

Case No.

About the pregnancy

1. Did you receive antenatal care?

2. How far along were you when you first met with a midwife?

3. Did you have any problems in pregnancy?

4. Did you smoke, drink, or take drugs in pregnancy?

5. Were you distressed during pregnancy?

6. Was this a multiple pregnancy?

About baby

7. Female/male

8. Was the baby born early? If so how early?

9. How was the baby delivered?

10. Were there any complications?

11. Did the baby need any medical care/resuscitation/help with breathing after birth?

12. Are you currently breast feeding?

\section{A.5 | Appendix 5}

Significant life events

Definition: change that has occurred since first home visit. Mother

1. Postnatal depression

2. Mental illness-other

3. Physical illness (requiring medical intervention)

4. Single teenage mother (without support)

Baby

1. Feeding difficulties with Failure to Thrive (FTT)

2. Medical illness (requiring medical opinion)

${ }^{1}$ Where possible this data will be extracted from the mothers' and infants' health records following receipt of consent. 
3. Developmental delay (requiring health professional opinion)

4. Extreme crying/colic (requiring intervention)

Relationships

1. Separated from partner

2. Illness in partner (requiring hospitalisation)

3. Death of partner

4. New relationship

5. Death of a significant ${ }^{1}$ relative
6. Illness in a significant relative ${ }^{2}$ (requiring hospitalization)

Family and home situation

1. Partner unemployed

2. Partner new job

3. Mother employed

4. Moved house/flat/bedsit

5. Others now living in household-increased support/decreased support 